\title{
Ascensão e distanciamento na trajetória social, escolar e profissional de um jovem das camadas populares
}

\author{
Luiz Fernando de Oliveira* \\ Écio Antônio Portes**
}

\section{Resumo}

O presente texto traz a análise da trajetória escolar, profissional e social de um ator social oriundo das camadas populares que ingressou em um curso superior altamente seletivo da Universidade Federal de Minas Gerais (UFMG) e o concluiu, a saber, o curso de Engenharia Elétrica, cursou o Mestrado na mesma área e trabalha como engenheiro em uma companhia energética no estado de Minas Gerais. As reflexóes levantadas neste trabalho dizem respeito, principalmente, às mudanças econômicas, culturais e sociais que foram ocorrendo na vida do referido ator no período que vai do ano de 1996, ano de seu ingresso na Universidade, até o ano de 2012, tendo como referência o papel da escola e da Educação, em sentido amplo, nesta trajetória de "sucesso". Como técnica de coleta de dados, foram realizadas entrevistas em profundidade em dois períodos diferentes, de modo a abarcar a escolarização e a vida profissional do ator pesquisado. Os resultados das análises apontam para duas hipóteses centrais: 1) a formação escolar e o ingresso no mundo do trabalho em uma profissão socialmente prestigiada não foram capazes de garantir, até aqui, a incorporação da cultura das elites pelo ator investigado, embora o mesmo tenha incorporado rapidamente a cultura profissional exigida pelo seu cargo, o que se mostrou altamente funcional; e 2) a ascensão social, econômica e cultural do ator parece ter produzido um distanciamento do mesmo em relação às suas origens, distanciamento seguido de certa carga de sofrimento.

Palavras-chave: Sociologia da Educação. Escolarização. Ascensão social.

\footnotetext{
* Mestre em Processos Socioeducativos e Práticas Escolares pela Universidade Federal de João Del-Rei (UFSJ). Doutorando em Educação pela Universidade Federal de Minas Gerais. Professor do curso de Psicologia do Centro Universitário de Lavras (UNILAVRAS)

** Doutor em Educaçáo pela Universidade Federal de Minas Gerais (UFMG). Professor do Departamento de Ciências da Educação e do Programa de Pós-graduação em Educação da Universidade Federal de Joáo DelRei (UFSJ).
} 
O presente trabalho é parte de pesquisas mais amplas inseridas entre os estudos qualitativos no campo da Sociologia da Educação, mais especificamente entre os estudos destinados à compreensão das trajetórias escolares de longa duraçáo de atores sociais provenientes dos meios populares. Trata-se de um estudo de caso individual sobre a trajetória escolar, profissional e social de Maurício, nome fictício de um ator oriundo de uma família pertencente às camadas populares, formado e pós-graduado em Engenharia Elétrica pela Universidade Federal de Minas Gerais (UFMG) e, nos dias atuais, Engenheiro Sênior de uma companhia energética em Minas Gerais. Os materiais empíricos utilizados são as transcriçôes de uma série de entrevistas realizadas com o ator entre os anos de 1996 a 1998 (período em que Maurício cursava os quatro primeiros semestres de Engenharia Elétrica) e também no ano de 2012 (quando foi sugerido um retorno ao mesmo ator, cerca de catorze anos após o encerramento das primeiras entrevistas).

Embora não se tenha a pretensão de criar generalizações a partir do caso de Maurício, visto que a singularidade da sua trajetória socioescolar impede qualquer raciocínio de ordem indutiva, é preciso mencionar que esse ator é uma figura paradigmática, visto ter superado o "quase total monopólio que as classes dominantes detêm sobre aquelas instituiçóes de Ensino Superior mais raras, seletivas e prestigiosas", evocando os termos de Nogueira (1991, p. 104). Em outras palavras, a trajetória socioescolar de Maurício é marcada por uma verdadeira luta contra um sistema educacional que ainda contribui para a manutenção dos privilégios das classes sociais dominantes. Conforme mostrou Elias (1995, p. 16), a figura do compositor Wolfgang Amadeus Mozart (1756-1791) "ilustra nitidamente a situação de grupos burgueses outsiders numa economia dominada pela aristocracia de corte, num tempo em que o equilíbrio de forças ainda era muito favorável ao establishment cortesão". No caso aqui analisado, a figura de Maurício representa os grupos "dominados" em busca pelo acesso aos níveis escolares que costumeiramente fazem parte apenas dos destinos escolares dos estudantes oriundos dos grupos dominantes. Assim, sua trajetória representa "aspectos individuais das tensóes sociais" (ELIAS, 1995, p. 17) aqui consideradas.

Nenhum ator pode ser compreendido de maneira isolada de seu contexto social e histórico, mas sim como um sujeito inserido em uma "rede de relaçôes", na expressão de Touraine (1984, p. 114). O "sentido do comportamento dos actores ${ }^{1}$ não se procura em princípios, numa ordem do universo ou num sentido da história; aliás, ele não está em lado algum que não seja nas relaçóes sociais de que esse actor faz parte" (TOURAINE, 1984, p. 165-166, grifo nosso). Contudo, nenhum ator é determinado mecanicamente por nenhum tipo de estrutura ou relação. Por isso mesmo, é necessário que a Sociologia "se afirme claramente como análise 'relacional', táo afastada do subjectivismo como do objectivismo" (TOURAINE, 1984, p. 75). 
Desde o início da década de 1990, na Sociologia da Educação, assim como em outras áreas, tem crescido o interesse por trajetórias escolares longevas entre atores dos meios populares. Pode-se citar, por exemplo, os seguintes trabalhos: Almeida (2006), Arenhaldt (2012), Carneiro (2010), Piotto (2007), Portes (1993, 2001), Silva (2003), Souza (2009), Viana (1998), entre outros. Contudo, pesquisas com atores dos meios populares que já concluíram o curso superior e que por ventura tenham ingressado no mundo do trabalho ainda não são comuns. Os estudos de Lacerda (2006) e Oliveira (2013) são dois raros exemplos de trabalhos que buscam suprir esta lacuna.

A ideia principal a partir da qual se trabalha aqui é a de uma ampliação da noçáo de "sucesso escolar". Além do acesso dos atores ao ensino superior e da permanência no mesmo, o ingresso no mundo do trabalho, a partir da formação universitária, também é considerada. Portanto, para o caso específico de Maurício, sucesso escolar é compreendido como o ingresso e a permanência no sistema escolar em nível superior como fatores que possibilitem o ingresso no mundo do trabalho em profissôes de prestígio social elevado, ou naquelas diretamente proporcionais ao capital escolar adquirido.

A seguir, apresentam-se a descrição da origem social e da trajetória socioescolar e profissional de Maurício, descrição que tem por objetivo apresentar o ator e sua configuração sociofamiliar.

\section{Origem social, trajetória socioescolar e trajetória profissional de Maurício}

Maurício é oriundo de uma cidade do interior de Minas Gerais, distante cerca de 150 quilômetros da capital Belo Horizonte. Sua família restrita é composta por seis membros: pai, mãe e quatro filhos, todos homens, dos quais Maurício é o segundo na fratria. A mãe de Maurício é dona de casa e o pai, falecido recentemente, trabalhou como raspador de taco e aplicador de sinteco, além de ter exercido vários outros trabalhos, todos braçais, ao longo da vida. Nenhum dos membros da família de Maurício, incluindo a sua família extensa, teve uma escolarização longa, com exceção de seu irmão mais novo, filho adotivo de seus pais, que concluiu o ensino médio ${ }^{2}$, embora com atraso.

Maurício estudou a vida toda em escola pública e, a partir do $7^{\circ}$ ano do ensino fundamental, começou a conciliar trabalho e estudos, transferindo-se para o período noturno da escola em que estudava. Mesmo sendo pertencente a uma família que sempre sofreu com as injunçôes econômicas e que possui um capital escolar limitado, Maurício se destacava na escola. Ele chamava a atenção dos professores pelo seu 
"potencial" e por sua dedicação, além de ter sido um aluno "competitivo", que gostava de "disputar" com alguns colegas para ver quem conseguiria tirar as melhores notas.

É fato que a trajetória escolar de Maurício na educação básica comporta oscilaçóes - uma reprovação no $6^{\circ}$ ano do ensino fundamental e uma queda brutal do seu rendimento no $8^{\circ}$ ano, quase ocasionando outra reprovação. Contudo, problemas pessoais, e não incapacidades de ordem cognitiva, levam a uma melhor compreensão dessas oscilaçôes, sendo o mais grave deles os abalos emocionais vividos por Maurício devido aos problemas de saúde da sua mãe e de seu irmáo mais velho, que sempre sofreram com "distúrbios psicológicos", em suas próprias palavras. Com efeito, o irmão mais velho de Maurício sempre passou e passa por constantes internações psiquiátricas.

Após o ensino médio, Maurício foi aprovado no final do ano de 1994 no vestibular para o curso de Direito da Universidade Federal de Ouro Preto (UFOP), mas não ingressou, voltando a ser aprovado em outro vestibular de alta seletividade, aquele para o curso de Engenharia Elétrica da UFMG, ao final do ano de 1995. Em síntese, Maurício ingressou no curso da UFMG, precisando se mudar para Belo Horizonte, onde morou praticamente "de favor" durante todo o período da graduação, sofrendo com questôes de ordem econômica, emocional e relacional. O jovem conseguiu se manter na capital mineira devido a auxílios recebidos da Fundação Universitária Mendes Pimentel (FUMP) ${ }^{3}$, a bolsas de Iniciação Científica e de Monitoria recebidas e a certos "bicos" feitos por ele como professor particular, basicamente de Matemática e de Física.

A trajetória universitária de Maurício também comporta oscilaçôes: foi reprovado em duas disciplinas, e suas notas, ao longo do curso, náo parecem ter sido "excelentes". Contudo, o curso foi concluído nos devidos cinco anos e Maurício ingressou imediatamente no Mestrado em Engenharia Elétrica da mesma instituição, conseguindo obter o título de Mestre nos devidos dois anos. Maurício atribui o seu "sucesso", entre outros fatores, ao fato de não ter precisado "trabalhar" para se manter na capital mineira, pois, caso precisasse conciliar trabalho e estudos, o seu desempenho acadêmico seria comprometido, devido ao alto nível de exigência de seu curso. Não obstante, o seu esforço individual parece ter sido o fator determinante, na análise do ator, para que ele atingisse seus objetivos. Tal análise aparece em uma espécie de "discurso do mérito", repetido constantemente pelo jovem durante os trabalhos de pesquisa realizados junto a ele.

Maurício ingressou, via concurso público, em uma companhia energética em Belo Horizonte, no ano de 2002, exercendo o cargo de Engenheiro Júnior. Oito anos depois, esse ator já havia sido promovido ao cargo de Engenheiro Sênior da companhia, em uma ascensão profissional considerada "rápida". 
Hoje, com trinta e sete anos de idade, mora com o irmão mais novo em um apartamento próprio na capital mineira, possui um automóvel, ajuda financeiramente a sua família no interior, participa constantemente de cursos de formação continuada e tem planos de fazer o Doutorado em Engenharia Elétrica.

A seguir, apresenta-se uma análise da vida social de Maurício, e também das suas inserçôes culturais, ou, na expressão de Lahire (2006, p. 486), o "perfil cultural" do ator investigado.

\section{O perfil cultural de Maurício}

A característica mais marcante do "perfil cultural" de Maurício é o seu "gosto pelos estudos". Embora seus pais e seu irmão mais velho fossem desprovidos de condiçôes de auxiliá-lo pedagogicamente, é fato que Maurício desenvolveu um habitus escolar diferenciado, o que propiciou a longevidade de sua escolarizaçáo. Chamboredon e Prévot (1973 apud NOGUEIRA 1991, p. 110) definiram habitus escolar como o "conjunto de disposiçóes face à escola e às tarefas escolares que enquanto princípios determinantes da relação com a aprendizagem escolar - tem boa probabilidade de exercer efeitos ao longo de toda a carreira escolar". De fato, Maurício enfatizou o gosto pelos estudos e pelo ambiente escolar durante toda a entrevista: "É... eu gostava. Eu gostava!", declarou com entusiasmo.

A causa principal da construção do habitus escolar de Maurício deve ser buscada em sua atmosfera familiar. Com efeito, embora inexista um investimento escolar racional, por parte dos pais, na escolarização do filho, a presença de uma "ordem moral doméstica” perpassa todo o seu processo de socialização. A ordem moral doméstica Portes (2010, p. 67, grifo do autor) compreende como "um esforço contínuo que não tem como alvo específico o sucesso escolar e, sim, uma educação mais abrangente, uma educação para a vida". É importante ressaltar, ainda, que aquele investimento escolar racional, que tem como objetivo uma escolarização longa, não é típico das famílias das camadas populares, mas sim das camadas sociais mais aquinhoadas econômica e culturalmente (NOGUEIRA, 1991, p. 94).

Por outro lado, é notável a presença de um "trabalho escolar" da sua família, imprescindível para a trajetória escolar (e social) trilhada por jovens de origem popular (PORTES, 2010). O "trabalho escolar da família" é a definição que abrange "todas aquelas açóes - ocasionais ou precariamente organizadas - empreendidas pela família no sentido de assegurar a entrada e a permanência do filho no interior do sistema escolar" (PORTES, 2010, p. 63). 
Os pais de Maurício são dotados de uma respeitabilidade, de modo especial a figura do pai, que foi capaz de inculcar nos filhos um gosto pelo trabalho e que, em Maurício, se converteu também em um gosto pelos estudos. É necessário ressaltar que a ética do trabalho presente na configuração familiar de Maurício fez com que todos os filhos assumissem, desde muito cedo, a responsabilidade de trabalhar para ajudar o pai na manutenção econômica da família. Contudo, Maurício sempre teve certas "regalias" que contribuíram para que ele pudesse se dedicar mais aos estudos: quando Maurício começou a ajudar seu pai no trabalho como aplicador de sinteco, o filho sempre teve a possibilidade de fazer um horário maleável, a fim de que pudesse estudar. Além de ajudar o pai no trabalho, aos treze anos de idade Maurício começou a trabalhar como aprendiz de marceneiro em sua cidade, e seu empregador lhe concedia as mesmas "regalias" que o pai: o patrão de Maurício era condescendente com sua vontade de estudar, pois sempre permitia a ele sair mais cedo do trabalho nos dias de prova na escola.

Outro aspecto importante para a compreensão do perfil cultural e do habitus escolar de Maurício diz respeito à presença de uma "solidariedade familiar" (LAHIRE, 1997) presente na família desse ator. Não há relatos a respeito de relaçóes envolvendo ciúmes, disputas internas ou qualquer tipo de hostilidade entre os irmãos, pelo contrário, todos parecem se orgulhar do irmão "inteligente", a ponto de fazer com que eles movessem esforços para que Maurício se mantivesse estudando. Um exemplo concreto dessa solidariedade é o fato de Maurício ser o único dos irmãos que tinha um quarto só para ele em sua modesta casa.

A influência parental na construção do habitus de Maurício se faz notar na presença de uma "ordem moral doméstica", na ética do trabalho, na respeitabilidade, no "trabalho escolar" de sua família e na "solidariedade familiar" que marcam sua configuração, características que parecem fazer parte do universo das famílias oriundas dos meios populares e que se fazem notar com clareza neste caso específico. A noção de habitus agora evocada, não é mais aquela especificamente escolar, mas a que diz respeito, de forma mais abrangente, ao comportamento social do ator, definida por Bourdieu (2003, p. 53-54, grifo do autor) como os "sistemas de disposiçôes duráveis, estruturas predispostas a funcionar como estruturas estruturantes, isto é, como princípio gerador e estruturador das práticas e representaçóes".

Um dos principais temores de Maurício refere-se aos "distúrbios psicológicos", em suas palavras, que sempre acometeram e acometem sua mãe e seu irmão mais velho. Por isso mesmo, foi na tentativa de inserir-se socialmente, de entreter-se, que o ator analisado procurou equilibrar a sua vida de trabalhos e estudos à época de seu curso superior, e ainda procura fazê-lo, pois, ao contrário da mãe e do irmáo mencionado, 
Maurício nunca se entregou ao "desespero". Maurício sabe que os momentos de lazer são necessários para o equilíbrio da sua "sanidade mental", por isso valoriza tanto esses momentos.

Contudo, a suas tentativas de inserção social foram um tanto difíceis, especialmente nos quatro primeiros semestres de seu curso na UFMG, isto é, no período chamado de Ciclo Básico. A título de elucidação, o Ciclo Básico engloba os quatro primeiros semestres do curso de Engenharia Elétrica e de outros cursos da UFMG. As disciplinas oferecidas são, em sua maioria, matrizes comuns a todos os demais cursos de uma mesma área daquela universidade. $\mathrm{O}$ ambiente onde acontecem as aulas, no caso dos cursos da área de Ciências Exatas, é o Instituto de Ciências Exatas (ICEX). Encerradas as disciplinas do Ciclo Básico, cada estudante é direcionado ao departamento específico do seu curso, a fim de cursar as disciplinas do Ciclo Profissional. No caso de Maurício, os seis últimos períodos de seu curso, cuja duração total é de dez períodos, passaram-se no Departamento de Engenharia Elétrica (DEE) da UFMG.

As dificuldades de inserção pelas quais passou Maurício nesse "novo mundo" foram de várias ordens, como costuma ser para os atores de origem popular, visto que, inserir-se social e culturalmente, não somente academicamente, em um meio táo distinto daquele de origem desses atores demanda a posse de dinheiro (para frequentar bares, festas, shows, teatro, cinema, entre outros ambientes), mas também de todo um conjunto de características distintivas, que faz com que eles sejam aceitos nesse mundo, se não de forma integral, ao menos de maneira menos conflituosa.

No caso de Maurício, a falta de dinheiro e das características distintivas assinaladas anteriormente tornaram tedioso o seu cotidiano nos primeiros semestres do seu curso, o que levou o jovem a declarar que "estava naquela lama, eu já falei isso, não é? Escola para casa, casa para escola. Então virou uma rotina”. É necessário destacar que a situação econômica de Maurício se agravou devido ao fato de esse ator sempre ter contribuído financeiramente com a sua família no interior, carreando para ela recursos que poderiam ser investidos em uma vida social mais proveitosa em Belo Horizonte.

Não obstante e apesar de todas as dificuldades, Maurício não se entregou a tais injunçôes, passando a buscar cada vez mais a sua inserção entre jovens socialmente "diferentes". Com o passar dos semestres, Maurício, apesar da distância econômica, passou a frequentar determinados ambientes que seus colegas mais aquinhoados frequentavam, e suas atitudes foram movidas por um esforço de integraçáo associado a um "sentimento de igualdade" que passou a fazer parte do habitus reconfigurado desse ator. Mesmo diante da péssima condição econômica, Maurício se recusava a submeterse aos ditames do rendimento acadêmico e a viver em função dele. Aliás, Maurício 
acredita que um bom rendimento acadêmico depende da utilização de circunstâncias capazes de distrair a tensão que os estudos provocam.

É interessante mencionar que Maurício e seu irmão mais velho são músicos amadores. No período da adolescência, ainda morando no interior, Maurício tocava, juntamente com o irmáo, em uma banda que já era um pouco reconhecida na regiáo. Maurício toca violáo e guitarra, considera-se um "autoditada" no aprendizado desses instrumentos e, morando em Belo Horizonte, participou de algumas bandas na faculdade e também tocou com amigos de fora da UFMG. A música aparece nos relatos desse ator como um importante elo entre ele e os demais atores com os quais conviveu e, certamente, o "talento" musical propiciou a Maurício condições de inserção necessárias para o seu equilíbrio emocional.

A respeito de viagens realizadas, Maurício praticamente ainda não havia viajado para conhecer outros lugares antes do ingresso na companhia em que trabalha. Foi justamente por causa da melhoria nas condiçóes econômicas associada à demanda de viagens a trabalho por parte da empresa que o jovem passou a conhecer, a princípio, boa parte das cidades do estado de Minas Gerais e, em seguida, outros estados do Brasil e também outros países.

É importante mencionar que, atualmente, o ator tem condições de viajar, e que efetuar viagens, para ele, é uma questão de "querer", e não mais de "poder". Contudo, ao que parece, grande parte das viagens feitas por Maurício estão associadas diretamente às suas atividades profissionais.

Algo notável no habitus de Maurício é o modo como ele conseguiu se apropriar da cultura profissional da empresa em que trabalha. Desde o seu ingresso na companhia, os seus superiores costumavam delegar a ele tarefas de alta responsabilidade e complexidade, as quais Maurício sempre conseguiu realizar de modo "competente", o que promoveu a ampliação de seu capital profissional e simbólico dentro da empresa.

De fato, todo o período universitário, com sua carga de sofrimento, mas também repleto de componentes pedagógicos, assim como a necessidade de inserção no mundo do trabalho e nos ambientes de nível social mais elevado, propiciaram a Maurício a oportunidade de reconfigurar o seu habitus em um novo processo de socialização, distinto daquele de sua socialização primária (BOURDIEU; PASSERON, 2011), e o resultado mais aparente deste processo é exatamente a incorporaçấo daquilo que Lahire (2006) chamou de "capital cultural profissional", modalidade do capital cultural que diz respeito às disposiçôes específicas exigidas pelo meio profissional no qual os atores se inserem. O "sucesso" no mundo do trabalho depende da incorporação deste tipo de capital cultural. 
Maurício sabe e declara que "empresa vive de resultados" e que o cumprimento eficiente daquilo que cabe a cada funcionário propicia o "reconhecimento" do mesmo, e que este tende a ser convertido em promoçôes por "mérito". Ainda conforme Maurício, o progresso dentro da companhia em que trabalha se dá conforme a "boa vontade" dos funcionários e as promoçôes "não são totalmente matemáticas, nem automáticas". Por esse motivo, o ator entrevistado procurou sempre cumprir com "dedicação", "esforço" e "competência" a todas as demandas da empresa que lhe eram conferidas.

Todas as vezes em que se tratou de assuntos relacionados ao seu trabalho durante a coleta de dados realizada para este estudo, Maurício abordou os temas com fluidez na fala e com uma expressão de grande satisfação, revelando uma incorporação rápida daquele tipo muito específico de capital cultural profissional, o que parece ter produzido nesse ator efeitos duradouros.

É preciso, contudo, que se faça aqui uma observação: apesar de uma satisfatória e eficiente incorporação do capital cultural profissional de seu meio, ao que parece, Maurício não conseguiu, até então, apropriar-se com a mesma intensidade da "cultura legítima”, ou das "práticas culturais legítimas" (DUMONTIER; SINGLY; THÉLOT, 1990), isto é, da "cultura das elites", quase sempre coincidente com a "cultura erudita". Com efeito, o ator apresenta-se sem desenvoltura ao tratar de assuntos ligados a esse tipo de cultura, e demonstra uma relação um tanto tensa e um ligeiro distanciamento em relação às práticas culturais das elites.

Obviamente, a definição acerca da "cultura legítima" é arbitrária e faz parte de todo um jogo de dominação social que cria hierarquias socioculturais, como mostrou, por exemplo, Lahire (2006). Porém, a discussão aqui é a seguinte: ainda que arbitrária, o fato é que há uma cultura considerada e aceita socialmente como legítima, e é deste tipo de cultura ou deste tipo de práticas culturais, que Maurício parece ainda manter certa distância.

Por esse motivo, levanta-se a hipótese de que a ascensão social e econômica, mesmo associada à posse de um elevado capital escolar, não proporciona, necessariamente, a médio prazo, a incorporaçáo pelos atores de origem popular da "cultura legítima" ou da "cultura erudita". Esses atores podem estar inseridos em contextos que exigem e propiciam a eles esta incorporação, e eles podem conseguir apropriar-se de forma satisfatória dos capitais culturais específicos de suas áreas, contudo, a incorporação da "cultura das elites" parece se dar por um processo distinto daquele que garante a incorporação do "capital cultural profissional".

Ressalta-se que a hipótese acima ainda não foi tratada de forma satisfatória pelos estudos em Sociologia da Educação, e que, por este motivo, é necessário que novos estudos se debrucem sobre este problema. Outro aspecto que aparece no perfil cultural 
de Maurício, e que ainda é pouco explorado, diz respeito a certo distanciamento que surgiu entre $\mathrm{o}$ ator e seus familiares, objeto da seção a seguir.

\section{O outro lado da ascensão sociocultural: distanciamento em relação às origens}

Para início desta seção, evoca-se a experiência socioescolar de Pierre Bourdieu. De família modesta, Bourdieu conseguiu ascender social e culturalmente, chegando a atingir os altos postos da hierarquia cultural, atribuindo-se, segundo Nogueira e Nogueira (2009) um "habitus clivado", ou seja, um padrão de comportamento incorporado, produto do forte contraste entre a sua consagração escolar (ou a posiçấo social por ele atingida) e sua origem social. Conforme Gonçalves e Gonçalves (2010, p. 16-17), Bourdieu chamava-se de "trânsfuga", isto é, uma espécie de "desertor" da sua classe social de origem, o que lhe acarretou inúmeros e variados sofrimentos, em detrimento das vantagens, por assim dizer, de sua ascensão sociocultural. Assim, o autor, com base em sua própria vivência, fornece subsídios teóricos para que sejam pensadas as "exceçôes", ou os alunos que passaram por um processo por ele denominado de "superseleçáo" (BOURDIEU, 2010).

O processo de superseleção pelo qual Maurício passou parece ter sido o causador daquele "sentimento de igualdade" anteriormente mencionado. Conforme Bourdieu (2010, p. 46), "a super-seleção dos estudantes oriundos dos meios menos favorecidos vem compensar a desvantagem inicial que devem à atmosfera cultural de seu meio". O processo de superseleçấo, embora não elimine as dissonâncias socioculturais entre os atores, ao menos as amenizam, ou mesmo dissimulam. Passar por tal processo fez com que Maurício se visse como um "igual", mesmo entre "diferentes", em detrimento de sua condição social. No entanto, o distanciamento escolar que surgiu entre ele e seus familiares parece ter se convertido em distanciamento social, afastando-o de seus "iguais" e aproximando-o dos "diferentes".

Percebem-se, na figura de Maurício, traços semelhantes aos acima mencionados: um ator de origem popular, que através da escolarização conseguiu atingir níveis sociais estatisticamente improváveis, mas que parece trazer em si uma bagagem de sofrimento, paradoxalmente produzido por sua ascensão sociocultural. Chama-se a atenção para este ponto, visto que ainda não são comuns estudos sobre os distanciamentos produzidos pela escolarização longa e pela inserçáo no mundo do trabalho em cargos socialmente prestigiados de atores provenientes dos meios populares. $\mathrm{Na}$ verdade, até agora, trabalhos com este tipo de objeto ou enfoque são 
desconhecidos, mesmo não se esquecendo do trabalho de Terrail (1990) e suas histórias de trânsfugas.

Mas, de que ordem exatamente podem ser considerados esses distanciamentos? Cabe ressaltar que eles náo são de ordem meramente econômica. Muito pelo contrário, a ascensão econômica de um dos membros de uma família parece produzir até mesmo um efeito de aproximação entre os familiares, aproximação revelada, no caso de Maurício, no fato de ele sempre ter ajudado a sua família, financeiramente falando, de forma especial nos dias de hoje, visto que ele costuma enviar, com certa frequência, quantias consideráveis de dinheiro para a sua mãe, que ainda vive no interior mineiro. Esta ajuda financeira tem alguma relação com uma espécie de "retribuição" à "solidariedade familiar" que permeou todo o processo de escolarizaçáo de Maurício.

Assim, os distanciamentos são muito mais de ordem simbólica que de ordem material. De fato, desde o seu ingresso na universidade, Maurício procurou vestir-se de maneira simples, com camiseta, calça jeans e tênis, mas sempre "composto", "arrumado". Nas palavras do ator: "tenho que vestir mais ou menos como os colegas, não pode destoar muito". Maurício sabe que, convivendo com atores socialmente "diferentes", náo pode mais ser como era antes, um "menino lá de.. não é?... chinelo... não é?... aquela simplicidade toda que era na minha vida". As formas de vestir revelam, desde o ingresso na universidade, um distanciamento necessário - e doloroso! - em relaçáo às origens.

As próprias visitas que os familiares de Maurício fazem a ele na capital mineira parecem não ser frequentes: os seus irmáos o visitam pouco e Maurício vai mais até o interior do que eles vêm para a capital, embora não tenha sido especificada a frequência dessas visitas. Interessante notar que Maurício vive em um apartamento próprio em Belo Horizonte e que somente o seu irmão mais novo mora com ele; mesmo assim, quando a sua mãe o visita ela costuma se hospedar na casa da avó de Maurício na capital mineira, uma casa simples em um bairro pobre. Para vê-la e passar alguns momentos com ela, Maurício é quem tem que se deslocar à casa da avó, o que revela certo desconforto social da mãe em ir até o apartamento do filho, localizado em um prédio que parece atender a certas fraçôes das classes médias belo-horizontinas.

Tanto os familiares de Maurício quanto os seus conterrâneos o veem como "alguém de sucesso", que "deu certo", como "o cara", expressôes que demonstram, não apenas uma "admiração" por parte daquelas pessoas, mas também soam como uma marca distintiva, como sinais do "afastamento" de Maurício em relação a elas.

Por fim, o próprio desconhecimento da mãe acerca do trabalho do filho denota esse distanciamento. Segundo o Maurício, sua mãe tem apenas uma vaga noção do que ele faz profissionalmente, e ela já chegou a perguntá-lo: "Para que serve mesmo Engenharia Elétrica?". 
Contudo, deve-se insistir que os distanciamentos produzidos pela ascensão sociocultural ainda não são plenamente conhecidos, e o que se apresenta aqui é uma tentativa de esboçar a construçáo de um objeto de análise potencialmente produtivo, sobre o qual cabem aprofundamentos em projetos futuros.

\section{Considerações finais}

A trajetória social, escolar e profissional de Maurício não pode ser tomada como modelo para aqueles outros jovens provenientes do mesmo meio social, justamente porque ela encerra um caráter de complexa singularidade na sua constituição. $\mathrm{O}$ seu caso revela as açôes e as estratégias de um ator que atingiu altos níveis escolares e profissionais, em um percurso ascendente, embora marcado por certas oscilaçóes, contradiçôes e por grandes esforços, e que não pode ser entendido "como um mero percurso, desinteressado, percorrido pelo sujeito de forma frouxa” (PORTES; CRUZ, 2007, p. 156).

O desempenho acadêmico de Maurício durante o período da sua graduação em Engenharia Elétrica foi satisfatório: o jovem teve duas reprovaçóes, ambas no Ciclo Profissional, e embora as suas notas tivessem sido, de um modo geral, "um pouco acima da média”, é inegável o mérito de Maurício por ter concluído o curso nos cinco anos previstos, o que o coloca, de certa maneira, em "pé de igualdade" com seus colegas mais favorecidos econômica e culturalmente. Se a trajetória escolar e acadêmica desse ator comporta oscilaçóes, isto não decorre de dificuldades cognitivas ou porque o jovem não tenha se esforçado o suficiente; pelo contrário, o gosto pelos estudos, a vontade e a capacidade de aprender são características desse ator. As maiores dificuldades surgiram, na maioria das vezes, devido aos problemas paralelos, como a dificuldade do jovem em sair do interior para morar em um grande centro, mesmo sem recursos econômicos e, talvez mais do que isso, os problemas de saúde de sua mãe e de seu irmáo mais velho, problemas que se tornaram um verdadeiro "fantasma" na vida de Maurício. Contudo, o que de mais importante revela a trajetória escolar de Maurício é que parece não haver uma relação estreita entre "brilhantismo" escolar e "sucesso" profissional. A trajetória desse ator desmistifica isso, pois, se Maurício foi um aluno que se destacava na educação básica, na universidade, considerando o curso escolhido e a competitividade imposta pelo mesmo, esse ator, além de sofrer reprovaçóes, foi um estudante ligeiramente acima da média, sem apresentar grandes destaques.

O caso de Maurício leva a entender, ainda, que a permanência do estudante de origem popular na universidade é fortemente devedora do fator econômico, especialmente naqueles cursos mais seletivos das universidades públicas. Não se podem descartar os fatores de outras ordens, como, por exemplo, emocional ou relacional, 
contudo, naquele tipo de curso, torna-se inviável aos estudantes a tentativa de conciliar um trabalho remunerado com os estudos, devido ao seu grau de exigência acadêmica. Os auxílios recebidos da FUMP garantiram a permanência de Maurício na UFMG e, sem eles o trancamento da matrícula e mesmo a desistência do curso, provavelmente, fariam parte do seu "destino escolar".

Maurício conseguiu atingir níveis escolares improváveis para um ator de origem popular, tornando-se Mestre em Engenharia Elétrica, e com planos de cursar o Doutorado. A sua formação e as suas disposiçôes para o trabalho proporcionaram galgar os altos postos da companhia energética em que trabalha, tudo isso em um processo competitivo relativamente rápido no mundo do trabalho. Não obstante, as inserçóes socioculturais de Maurício ainda parecem marcadas pelos limites culturais da sua origem social. Não é de se desconsiderar o fato de que as situaçôes vividas por ele na Universidade e no trabalho tenham sido educativas, em sentido amplo, pois tudo o que ele vivenciou e vivencia nessas situações vem promovendo reconfiguraçóes constantes em seu habitus. Porém, retomando a hipótese anteriormente levantada, observando o caso de Maurício, a ascensão econômica, mesmo associada à posse de um elevado capital cultural institucionalizado, parece náo proporcionar, necessariamente, em médio prazo, a inserção dos atores de origem popular na "cultura legítima" ou na "cultura erudita", mesmo que esses atores estejam inseridos em contextos que exigem e propiciam isso, ainda que eles consigam apropriar-se de forma satisfatória dos capitais culturais específicos de suas áreas.

A trajetória social, escolar e profissional de Maurício apresenta ações, por parte desse ator e de sua família, que a princípio foram marcadas por incertezas e impossibilidades. Contudo, aquelas açôes marcadas pela insegurança foram dando lugar a novas estratégias estruturadas pelo habitus socialmente reconfigurado de Maurício, que passou a construir suas possibilidades de acordo com as circunstâncias, mas não permitindo que essas circunstâncias o limitassem ou o imobilizassem. Assim, analisando o comportamento social de Maurício nos dias atuais, aquilo que a princípio pode parecer uma indecisáo, na verdade trata-se de uma estratégia, altamente funcional, que pode levar a enganos por não apresentar a certeza daquelas estratégias planejadas racionalmente, típicas das camadas sociais mais privilegiadas no jogo social pela posse de um capital econômico ou cultural. Assim, passou a existir nas açôes e estratégias de Maurício um comportamento ascético, uma "segurança" mascarada de "insegurança", um "pé atrás", como se costuma dizer, que parece ser típico dos atores de origem popular que conseguem uma ascensão social, escolar e econômica, e essas disposiçôes foram surgindo por meio das relações sociais estabelecidas por Maurício, as quais foram reconfigurando o habitus desse ator social. 
Embora impossibilitados de proporcionar ao filho um estreito acompanhamento pedagógico, é inegável que o comportamento dos pais de Maurício apresenta traços de uma "pedagogia moral", ou de uma "educaçáo para a vida" (PORTES, 2001). O fato de o pai, a máe e também os irmãos de Maurício terem movido grandes esforços para que ele continuasse estudando, revela igualmente aquela "solidariedade familiar", assinalada por Lahire (1997), presente nas famílias dos meios populares. A valorizaçáo da escola marca igualmente o comportamento dos pais de Maurício, embora não apareçam declarações explícitas a esse respeito durante o processo de pesquisa, é inegável que o pai e a mãe de Maurício, e mesmo os seus irmãos, moveram grandes esforços para manterem o filho "inteligente" estudando. De acordo com Lahire (1997, p. 334), entre a sua amostragem de vinte e seis famílias dos meios populares entrevistadas, quase todos os pais, "qualquer que seja a situação escolar da criança, têm o sentimento de que a escola é algo importante e manifestam a esperança de ver os filhos 'sair-se' melhor do que eles". Continua o autor:

Aliás, é importante destacar que os pais, ao exprimir seus desejos quanto ao futuro profissional dos filhos, tendem, frequentemente, a desconsiderar-se profissionalmente, a "confessar" a indignidade de suas tarefas: almejam para sua progênie um trabalho menos cansativo, menos sujo, menos mal-remunerado, mais valorizador que o deles (LAHIRE, 1997, p. 334).

A despeito de toda a ajuda externa (de familiares, de amigos, de professores e de instituiçôes), não se pode desprezar nas trajetórias como as de Maurício, ditas de "sucesso", o esforço individual dos atores, a capacidade dos atores de se expressarem e de irem galgando postos cada vez mais elevados, adaptando-se às circunstâncias, de forma determinada, mesmo que em outro tempo, devagar, "degrau a degrau", mas sem retrocessos.

Por fim, retoma-se o fato de que o sucesso escolar e profissional de Maurício fez surgir um distanciamento entre ele e seus familiares. Contudo, ficam alguns questionamentos. De que ordem é esse tipo de distanciamento que ocorre entre os atores como aqui investigado? A pergunta é pertinente, pois esse tipo de distanciamento ainda é pouco explorado pelos trabalhos na área da Sociologia da Educação. Foi levantada aqui a hipótese de que esse distanciamento faz com que a ascensão social, escolar e profissional produza uma carga de sofrimentos nos atores de origem popular, sofrimentos que parecem ser fruto de um conflito vivido na transição de uma condição social a outra. Ocupar uma nova posição social parece exigir dos atores um afastamento 
de suas origens, talvez uma negaçáo delas, ao empreenderem atitudes e comportamentos que os fazem "se esquecer de onde vieram", como se costuma dizer, hipótese que parece ser reforçada pela inserção de Maurício no mundo do trabalho, pela posição que ele ocupa, por atitudes e comportamentos que podem ser vistos na forma de morar, nas viagens, nos equipamentos utilizados, nas tentativas de inserção cultural, na forma de se vestir, de comer e de falar de si entre outras manifestaçóes.

Com nostalgia, Maurício evocou, em uma entrevista, versos do poema Confidência do itabirano, de Carlos Drummond de Andrade (1902-1987), para se referir à improbabilidade de retornar à sua cidade natal para viver. Assim como para Drummond de Andrade (2008, p. 12) "Itabira é apenas uma fotografia na parede. Mas como dói!", para a "dor" de Maurício, sua cidade natal também pode ser apenas uma fotografia na parede, ou um local para onde ele dificilmente poderá retornar para viver. Esses distanciamentos compóem um potencial objeto ao qual é preciso se dedicar em estudos futuros.

\section{Notas}

${ }^{1}$ Em todas as citaçóes neste trabalho respeita-se a grafia da forma como aparece nas ediçóes dos textos utilizadas.

${ }^{2}$ Utiliza-se, neste texto, a nomenclatura atual dos cursos, com base na Lei de Diretrizes e Bases da Educação Nacional (LDB) no 9.394, de 1996 (BRASIL, 1996), embora Maurício e seus familiares tenham estudado, também, sob a vigência de legislaçôes anteriores.

${ }^{3}$ Instituição encarregada de prestar assistência alimentar, médica, odontológica, pedagógica, psiquiátrica e social aos estudantes pobres da UFMG. Para tal, a FUMP lança mão de um rigoroso estudo socioeconômico.

${ }^{4}$ Maurício não quis fornecer seus históricos escolares e nenhum outro documento para a pesquisa, por não querer "se expor além do necessário". Embora fosse possível ter acesso a esses documentos por outros meios, a vontade do entrevistado foi respeitada.

\section{REFERÊNCIAS}

ALMEIDA, Wilson Mesquita de. Esforço contínuo: estudantes com desvantangens sócio-ecônomicas e educacionais na USP. 2006. 136 f. Dissertação (Mestrado em Sociologia) - Universidade de São Paulo, São Paulo, 2006. 
ANDRADE, Carlos Drummond de. Sentimento do mundo. Rio de Janeiro: MEDIAFashion, 2008.

ARENHALDT, Rafael. Vidas e conexóes (in)tensas na UFRGS: o programa Conexôes de Saberes como uma pedagogia do estar-junto na Universidade. 2012. 254 f. Tese (Doutorado em Educação) - Universidade Federal do Rio Grande do Sul, Porto Alegre, 2012.

BOURDIEU, Pierre. Esboço de uma teoria da prática. In: ORTIZ, Renato (Org.) $A$ Sociologia de Pierre Bourdieu. São Paulo: Olho d'Agua, 2003. p. 39-72.

BOURDIEU, Pierre. A escola conservadora: as desigualdades frente à escola e à cultura. In: NOGUEIRA, Maria Alice.; CATANI, Afrânio (Org.). Pierre Bourdieu: escritos de educação. Petrópolis, RJ: Vozes, 2010, p. 39-64.

BOURDIEU, Pierre; PASSERON, Jean-Claude. A reprodução: elementos para uma teoria do sistema de ensino. Petrópolis, RJ: Vozes, 2011.

BRASIL. Lei no 9.394, de 20 de dezembro de 1996. Estabelece as diretrizes e bases da educação nacional. Diário Oficial da União, Brasília, DF, 23 dez. 1996.

Disponível em <http://www.planalto.gov.br/ccivil_03/Leis/L9394.htm>. Acesso em: 29 maio 2015.

CARNEIRO, Ava da Silva Carvalho. Caminhos universitários: a permanência de estudantes de origem popular em cursos de alto prestígio. 2010. $102 \mathrm{f}$. Dissertação (Mestrado em Psicologia) - Universidade Federal da Bahia, Salvador, 2010.

DUMONTIER, Françoise.; SINGLY, François de.; THELOT, Claude. La lecture moins attractive qu'il y a vingt ans. Économie et statistique, Paris, 1990, n. 233, p. 63-80.

ELIAS, Norbert. Mozart, sociologia de um gênio. Rio de Janeiro: Zahar. 1995.

GONÇALVES, Nádia; GONÇALVES, Sandro. Pierre Bourdieu: educação para além da reprodução. Petrópolis, RJ: Vozes, 2010.

LACERDA, Wânia Maria Guimarães. Famílias e filhos na construção de trajetórias escolares pouco prováveis: o caso dos Iteanos. 2006. $416 \mathrm{f}$. Tese (Doutorado em Educação) - Universidade Federal Fluminense, Niterói, 2006.

LAHIRE, Bernard. Sucesso escolar nos meios populares: as razôes do improvável. São Paulo: Ática, 1997.

LAHIRE, Bernard. A cultura dos individuos. Porto Alegre: Artmed, 2006. 
NOGUEIRA, Maria Alice. Trajetórias escolares, estratégias culturais e classes sociais: notas em vista da construçáo do objeto de pesquisa. Teoria \& Educação, Porto Alegre, n. 3, p. 89-112, 1991.

NOGUEIRA, Maria Alice; NOGUEIRA, Cláudio M. Martins. Bourdieu \& a educação. Belo Horizonte: Autêntica, 2009.

OLIVEIRA, Luiz Fernando de. $O$ retorno ao ator: um estudo de caso sobre a trajetória escolar e profissional de longo curso de um jovem das camadas populares. 2013. 148 f. Dissertação (Mestrado em Educação) - Universidade Federal de São João Del-Rei, São João del-Rei, MG, 2013.

PIOTTO, Débora Cristina. As exceçóes e suas regras: estudantes das camadas populares em uma universidade pública. 2007. 361 f. (Doutorado em Psicologia) Universidade de São Paulo, São Paulo, 2007.

PORTES, Écio Antônio. Trajetórias e estratégias escolares do universitário das camadas populares. 1993. 248 f. Dissertação (Mestrado em Educação) - Universidade Federal de Minas Gerais, Belo Horizonte, 1993.

PORTES, Écio Antônio. Trajetórias escolares e vida acadêmica do estudante pobre da UFMG: um estudo a partir de cinco casos. 2001. $267 \mathrm{f}$. Tese (Doutorado em Educação) - Universidade Federal de Minas Gerais, Belo Horizonte, 2001.

PORTES, Écio Antônio. O trabalho escolar das famílias populares. In:

NOGUEIRA, Maria Alice; ROMANELLI, Geraldo; ZAGO, Nadir (Org.). Família e escola: trajetórias de escolarização em camadas médias e populares. Petrópolis, RJ: Vozes, 2010. p. 61-80.

PORTES, Écio Antônio; CRUZ, Ricardo Alexandre da. Trajetórias e estratégias sociais e escolares do mulato José Rubino de Oliveira (1837-1891): da selaria em Sorocaba às Arcadas Jurídicas do Largo de São Francisco, São Paulo. In: PEREIRA, Lúcia Helena Pena; OLIVEIRA, Wanderley Cardoso de (Org.). Práticas educativas: discursos e produção de saberes. Rio de Janeiro: E-Papers, 2007. p. 147-169.

SILVA, Jailson de Souza e. Porque uns e não outros? Caminhada de jovens pobres para a universidade. Rio de Janeiro: Sete Letras, 2003.

SOUZA, Maria do Socorro Neri Medeiros de. Do seringal à universidade: o acesso das camadas populares ao ensino superior público no Acre. 2009. 214 f. Tese (Doutorado em Educação) - Universidade Federal de Minas Gerais, Belo Horizonte, 2009. 
TERRAIL, Jean-Pierre. Destins ouvriers, la fin d'une classe? Paris: PUF, 1990.

TOURAINE, Alain. $O$ retorno do actor: ensaio sobre sociologia. Lisboa: Instituto Piaget, 1984.

VIANA, Maria José Braga. Longevidade escolar em famílias de camadas populares: algumas condições de possibilidades. 1998. 302 f. Tese (Doutorado em Educação) Universidade Federal de Minas Gerais, Belo Horizonte, 1998. 


\section{Rise and distancing in the social, school and professional career paths of a young man from the lower classes}

\begin{abstract}
The present text analyses the professional, social and school trajectory of a social actor who came from the lower classes and who graduated at the Federal University of Minas Gerais in a very prestigious course in Electrical Engineering, took a Masters' degree in the same area and was employed as an engineer in an energy plant in Minas Gerais. The ideas developed in this work relate mainly to the cultural, social and economical changes which took place in the actor's life from the year 1996, when he entered the University, to the year 2012, taking into consideration the role of the school and of education, broadly speaking, in this "successful" trajectory. As data collection technique, in-depth interviews were conducted in two different periods in order to cover the schooling and the professional life of the researched actor. The result of the analysis points to two central hypotheses: 1) the school formation and afterwards the insertion into the work market in a highly prestigious profession were not sufficient to guarantee, up to now, the incorporation of the elite culture by the actor studied here, although he has quickly incorporated the professional culture demanded by his status, something that was highly functional in his work; and 2) the social, cultural and economical ascension of the actor seems to have distanced him from his original environment, such distancing having brought with it a certain amount of suffering.
\end{abstract}

Keywords: Sociology of Education. Schooling. Social rise.

\section{Ascension et détachement dans la trajectoire sociale, scolaire et professionnel $d^{\prime} u n$ jeune des classes populaires}

\section{Résumé}

Cet article présente l'analyse de la trajectoire sociale, professionnel et social d'un acteur social provenant des classes populaires, qui est entré dans un cours supérieur hautement sélectif dans l'Université Fédérale de Minas Gerais (UFMG) et l'a conclu, à savoir, le cours d'Ingénierie Électrique. Après, il a fait son Master dans le même domaine de connaissance et travaille comme ingénieur dans une compagnie d'énergie électrique de l'état de Minas Gerais. Les réflexions faites dans cette étude concernent, notamment, dans les changements économiques, culturels et sociaux qui ont eu lieu dans la vie de ce acteur entre 1996, l'année de son entrée à l'Université, jusqu'à l'année de 2012, ayant comme référence le rôle de l'école et de l'Éducation, au sens large, dans ce parcours de "succès". Comme technique de collecte de données ont été interviews en profondeur pendant deux diffèrent périodes, de façon à couvrir la scolarité et la vie professionnelle de l'acteur interviewé. Les résultats des analyses indiquent deux hypothèses centrales: 1) la formation scolaire et l'entrée dans le monde du travail dans un métier socialement prestigieux n'ont pas été capables d'assurer, jusqu'à ici, l'incorporation de la culture des élites par l'acteur, même s'il a incorporé rapidement la culture professionnelle requise par sa position, ce qui s'est avéré très fonctionnel; et 2) l'ascension sociale, économique et culturel de cet acteur semble avoir produit son détachement de ses origines, détachement suivi d'une certaine quantité de souffrance.

Mots-clés: Sociologie de l'Éducation. Scolarité. Ascension sociale. 


\section{Luiz Fernando de Oliveira}

E-mail: luizfernandodeoliveira@gmail.com

\section{Écio Antônio Portes}

E-mail: eaportes@gmail.com

Recebido em: 26/12/2013

Aprovado em: 29/8/2014 